\title{
Primary mucinous carcinoma of thyroid gland with prominent signet-ring-cell differentiation: a case report and review of the literature
}

This article was published in the following Dove Press journal:

OncoTargets and Therapy

\author{
Jian Wang ${ }^{1,2}$ \\ Qie-Re Guli \\ Xiao-Cui Ming ${ }^{3}$ \\ Hai-Tao Zhou ${ }^{3}$ \\ Yong-Jie Cui ${ }^{3}$ \\ Yue-Feng Jiang ${ }^{1,2}$ \\ Di Zhang ${ }^{1,2}$ \\ Yang Liu ${ }^{1,2}$ \\ 'Department of Pathology, The First \\ Affiliated Hospital and College of \\ Basic Medical Sciences, China Medical \\ University, Shenyang, China; ${ }^{2}$ Institute \\ of Pathology and Pathophysiology, \\ China Medical University, Shenyang, \\ China; ${ }^{3}$ Department of Pathology, The \\ People's Hospital of Tacheng Region, \\ Tacheng, China
}

Correspondence: Yang Liu Department of Pathology, The First Affiliated Hospital and College of Basic Medical Sciences, China Medical University, Shenyang, II000I, China

Tel +8618900910317

Fax +862423261638

Email liuyanglyon@cmu.edu.cn
Purpose: This study reports a case of primary mucinous carcinoma of the thyroid gland with signet-ring-cell differentiation, and reviews the literature to evaluate its real incidence and the prognosis of these patients.

Patients and methods: A 74-year-old Chinese woman, presenting with a mass in the right lobe of thyroid gland, came to the hospital. Computed tomography revealed a mass in the right lobe of the thyroid gland, accompanied with right neck lymphadenectasis and airway deviation caused by tumor compression. Thyroid imaging suggested a thyroid malignant tumor and suspicious lymph node metastasis. Histologically, the tumor was characterized by the tumor cells arranged in small nests or trabeculae with an abundant extracellular mucoid matrix. The tumor cells formed diffuse invasion among thyroid follicles. In the peripheral regions, prominent signet-ring-cells formed a sheet-like structure and extended into the extrathyroidal fat tissue. The tumor cells were diffusely positive for thyroid transcription factor-1 (TTF-1) and PAX8, while they were focally positive for pan-cytokeratin (AE1/AE3) and weakly expressed thyroglobulin.

Results: Based on the histological features and immunohistochemical profile, a diagnosis of primary mucinous carcinoma of the thyroid gland with signet-ring-cell differentiation was rendered.

Conclusion: Using a panel of immunohistochemical markers may be helpful for differential diagnosis and for determining whether the tumor is primary or not.

Keywords: mucinous carcinoma, primary thyroid cancer, signet-ring-cell differentiation, immunohistochemistry

\section{Introduction}

Primary mucinous carcinoma of the thyroid gland is extremely rare, and only eight cases have been reported in English-language literature, to our knowledge. ${ }^{1-9}$ It was first described by Diaz-Perez et $\mathrm{al}^{2}$ in 1976 . The histologic hallmark of this kind of tumor is small nests, trabeculae, or sheets of epithelial cells, which appear suspended in pools of abundant extracellular mucus. ${ }^{1}$ Histologically, it resembles the mucinous carcinoma of other sites, such as the breast, colon, stomach, and pancreas. ${ }^{1}$ Once the malignancy is confirmed, it is important to distinguish between primary and metastatic, as the subsequent treatment is different. In addition, mucinous appearance sometimes may be found in typical thyroid carcinoma or adenoma. ${ }^{10}$ Therefore, mucinous appearance, in itself, is insufficient to be diagnosed as malignancy. In this case, cervical lymph node metastasis is an important clue for rendering a definite diagnosis of malignancy in frozen sections. It was further demonstrated by observing the extrathyroidal infiltration by tumor cells in formalin-embedded sections. Primary mucinous carcinoma of the thyroid gland with 
prominent rhabdoid feature was reported recently. We also observed a similar feature in this case, but we would rather like to use signet-ring-cell differentiation to explain this phenomenon, because the immunohistochemical profile (Desmin-, MyoD1-), intra- and extracellular mucus confirmed by periodic acid-Schiff diastase (D-PAS) and alcian blue and periodic acid-Schiff(AB-PAS) staining both supported signet-ring-cell differentiation instead of rhabdoid differentiation. Immunohistochemical studies revealed that thyroid transcription factor-1 (TTF-1), PAX8, and thyroglobulin were positive, which indicated the thyroid origin of this tumor.

\section{Case presentation Clinical history}

A 74-year-old Chinese woman was admitted to our hospital, with a mass in the right lobe of thyroid gland for 7 days, which had been found during physical examination. She experienced an esophageal surgery for leiomyoma 20 years ago. Ultrasound showed an oval hypoechoic region beside the right lobe of thyroid with relative clear boundary. The internal echo pattern distribution in the lesion was uneven, containing areas of extremely low-level echoes. Computed tomography (CT; $27 \mathrm{HU}$; Figure 1A-C) showed an oval mass $(3.2 \times 1.4 \mathrm{~cm})$ with low-attenuation in the right lobe of thyroid and a round nodule with discontinuous peripheral annular calcification. Enlarged right neck lymph nodes were accompanied with airway deviation caused by tumor compression. Thyroid imaging suggested a thyroid malignant tumor, suspected to be lymph node metastasis and invasion of sternocleidomastoid muscle. Additional systematic laboratory tests indicated thyroid disfunction (thyroid-stimulating hormone [TSH] was elevated at $7.532 \mathrm{IU} / \mathrm{mL}$ [normal range $=0.55-4.78 \mathrm{IU} / \mathrm{mL}]$ ), while $\mathrm{T} 3$, thyroxine, F-T3, and free thyroxine were normal level (T3 $0.990 \mathrm{ng} / \mathrm{mL}$, thyroxine $5.60 \mu \mathrm{g} / \mathrm{dL}$, F-T3 $2.99 \mathrm{pg} / \mathrm{mL}$, free thyroxine $1.00 \mathrm{ng} / \mathrm{dL}$ ); antithyroglobulin and antithyroperoxidase antibody were both elevated (antithyroglobulin $>500 \mathrm{U} / \mathrm{mL}$, antithyroperoxidase antibody $>1,300 \mathrm{U} / \mathrm{mL}$ ), and the remaining parameters were normal calcium levels $(8.7 \mathrm{mg} / \mathrm{dL})$, carcinoembryonic antigen (CEA) levels $(1.87 \mathrm{ng} / \mathrm{mL})$, carbohydrate antigen 125 (CA125) levels (2.6 U/mL), carbohydrate antigen 15-3 (CA15-3) levels $(6.1 \mathrm{U} / \mathrm{mL})$, carbohydrate antigen 19-9 (CA199) levels (12.4 U/mL), AFP levels (2.60 ng/mL), serum ferritin (SF) levels $(25.7 \mathrm{ng} / \mathrm{mL})$, and calcitonin levels $(23 \mathrm{pg} / \mathrm{mL})$. None of the findings indicated medullary carcinoma or metastatic carcinoma. The patient underwent thyroidectomy, and rapid intraoperative pathological diagnosis suggested a poorly differentiated thyroid carcinoma with mucin-producing and cervical lymph node metastasis. During the operation, the surgeon also found some tan-white spots on the surface of the left lobe. Therefore, the operation was revised to hemithyroidectomy plus excision of cervical regional lymph nodes. The right lobe was $11 \times 6 \times 2.5 \mathrm{~cm}$ in size, the cut section showed a colloid nodule $(5.6 \times 4 \times 2.5 \mathrm{~cm})$ and a nodule $(3 \mathrm{~cm}$ in diameter $)$ with inconsecutive annular calcification. The colloid nodule demarcated from the surrounding tissue with obscure boundaries. Focal calcification was found in the surrounding thyroid tissue. The left lobe and the enlarged cervical lymph nodes were $3.5 \times 1.8 \times 1 \mathrm{~cm}$ and $2.3 \times 1.5 \times 0.8 \mathrm{~cm}$, respectively, in size with a flesh-colored cut surface. Considering the rarity of the primary mucinous carcinoma of the thyroid gland, additional positron emission tomography (PET)/CT scanning was performed after surgical operation and found no signs suspicious for tumor outside the thyroid or tumor recurrence. The patient underwent radiotherapy after surgery and is alive with no sign of tumor recurrence or metastasis after 9 months of follow-up.

\section{Patients and methods}

Bilateral thyroid mass and the cervical regional lymph nodes were completely sampled following the routine guidelines of
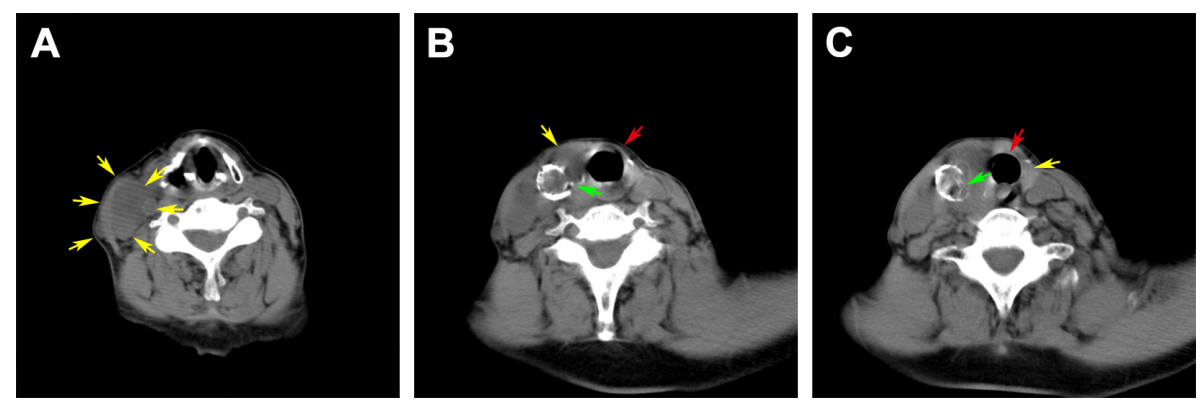

Figure I Imaging examination results. (A) The yellow arrows indicate the enlarged right cervical lymph nodes, which were suspicious for metastasis. (B) CT showed an oval mass with low attenuation in the right lobe of the thyroid and a round nodule with discontinuous peripheral annular calcification. (The yellow arrow indicates the tumor; the green arrow indicates the tumor focally broke into the nodule below and caused the interruption of the annular calcification; the red arrow indicates airway deviation caused by tumor compression). (C) The yellow arrow indicates the left lobe of the thyroid gland; the red arrow indicates airway deviation caused by tumor compression; the green arrow indicates a nodule with interruption of the annular calcification.

Abbreviation: CT, computed tomography. 
sampling $1 \mathrm{block} / \mathrm{cm}$ of tumor. All specimens were fixed in $10 \%$ formalin and embedded in paraffin. A series of $4-\mu m-$ thick sections was cut from each paraffin-embedded block. Commercially available prediluted monoclonal antibodies directed against epithelial membrane antigen (EMA), pan-cytokeratin (AE1/AE3), CK19, TTF-1, PAX8, thyroglobulin, calcitonin, CEA, CDX2, ER, GATA-3, vimentin, Desmin, MyoD1, myogenin, CD34, CD38, CD68, and Ki-67 were purchased from Mai Xin Inc. (Fuzhou, China). IHC staining was performed using the streptavidin-peroxidase system (ultrasensitive; Mai Xin Inc.) according to the manufacturer's instructions. The primary antibody was replaced with phosphate-buffered saline as for negative controls.

\section{Microscopic features}

Two different types of tumor were found in the mass occupying the right lobe of thyroid gland: one is a typical follicular adenoma, and no definite vascular invasion was seen in the capsule; the other one is a mucinous carcinoma. In most areas, the tumor cells were arranged in small nests or trabeculae, which appeared suspended in pools of abundant extracellular mucus (Figure 2A). These tumor cells not only invaded into normal tissues, destructing normal thyroid structures (Figure 2B and $\mathrm{C}$ ), but also extended into extrathyroidal fat tissue. In the peripheral regions, the tumor cells were aggregated and characterized by acidic muco-substances that diffusely fill the cytoplasm and dislodge the nucleus to one pole of the cell (Figure 2D and E). These signs were consistent with the second cytological type of carcinomas with signet-ring-cell differentiation, which were usually observed in gastric and breast carcinomas. In the remaining thyroid tissues, we can observe the background of Hashimoto's thyroiditis. Squamous differentiation was not seen. The mitotic activity was about two mitoses per high power field. Necrotic foci as well as areas with inflammatory infiltration were present. The cervical lymph node metastases and the left lobe exhibited similar histological features.

\section{Immunohistochemistry}

The tumor cells were diffusely positive for TTF-1 (Figure 3A and B), PAX8 (Figure 3C and D), and vimentin (Figure $3 \mathrm{E}$ ), and focal positive for AE1/AE3 and thyroglobulin, but negative for EMA, CDX2, ER, GATA-3, CEA, calcitonin, CD68, CD38, CK19, Desmin (Figure 3F), MyoD1 (Figure 3G), and myogenin. CD34 outlined vascular structures with no definite vascular invasion. The Ki-67 labeling index was $\sim 10 \%$. The abundant extracellular mucoid matrix and intracellular mucus in the signet-ring-cell were stained positively for D-PAS and AB-PAS (Figure 3H).

\section{Discussion}

Primary mucinous carcinoma of the thyroid gland was first described by Diaz-Perez et $\mathrm{al}^{2}$ in 1976; it was extremely rare, and English literature review on PubMed (www.ncbi.nlm.nih. gov) revealed only eight cases reported to our knowledge. ${ }^{1-9}$ Because of the rarity of this thyroid carcinoma, we discuss this case in the context of a literature review of previously reported cases (summarized in Table 1). The patients were aged $32-82$ years, and there was no sex predominance. This tumor favors to accompany with lymph node metastasis (8/9 cases). Grossly, this tumor presents as well- or poorly circumscribed gelatinous nodule. Taken together with this case, two cases have been reported to accompany with thyroid adenoma. This tumor is characterized by abundant mucoid lakes around trabeculae or clusters of tumor cells that usually show large nuclei and prominent nucleoli. In the present case, the nuclei with irregular contours were also observed, which has been reported by Sobrinho-Simoes et al. ${ }^{3}$ Recently, Matsuo et $\mathrm{al}^{7}$ found a rare histological feature of this tumor and used "rhabdoid" to describe it. We also observed the similar feature in our case, but we prefer to use signet-ring-cell differentiation to describe. These tumor cells were positive for TTF-1, PAX8, and thyroglobulin instead of Desmin, myogenin, or MyoD1. It is worth mentioning that the similar features were not uncommon in mucinous carcinoma of other organs, such as stomach, ovary, and breast, and usually be described as carcinomas with signet-ring-cell differentiation. ${ }^{11-13}$

In addition, we need to be aware the production of mucin in itself is insufficient to lead to a diagnosis a thyroid carcinoma. A couple of thyroid tumors may produce mucin such as adenomas, papillary carcinoma, anaplastic, and medullary carcinoma. 1,5,8,11,14 Moreover, primary thyroid carcinomas with signet-ring-cell differentiation were usually observed in follicular adenomas. ${ }^{15-17}$ Therefore, it is still a challenge to make a diagnosis of malignancy with mucin-producing tumor in rapid intraoperative frozen sections. In such situations, trying to find evidence of lymph node metastases, capsular penetration, or vascular invasion will be helpful to enhance the confidence to make a diagnosis of malignancy, just like the cervical lymph node metastasis in this case. It is worth mentioning that primary mucinous carcinoma seemed always circumscribed by inflammatory exudate and fibrous connective tissue and formed "pushing" invasion in previous reports, ${ }^{2,3,6,7}$ while in this case, the tumor cells formed diffuse infiltration among the normal thyroid follicles and destructed the normal thyroid structures. This phenomenon was seldom observed in the previous cases, but it is more likely to reflect the invasive biological behavior of the tumor. Whether these biological features indicated a 

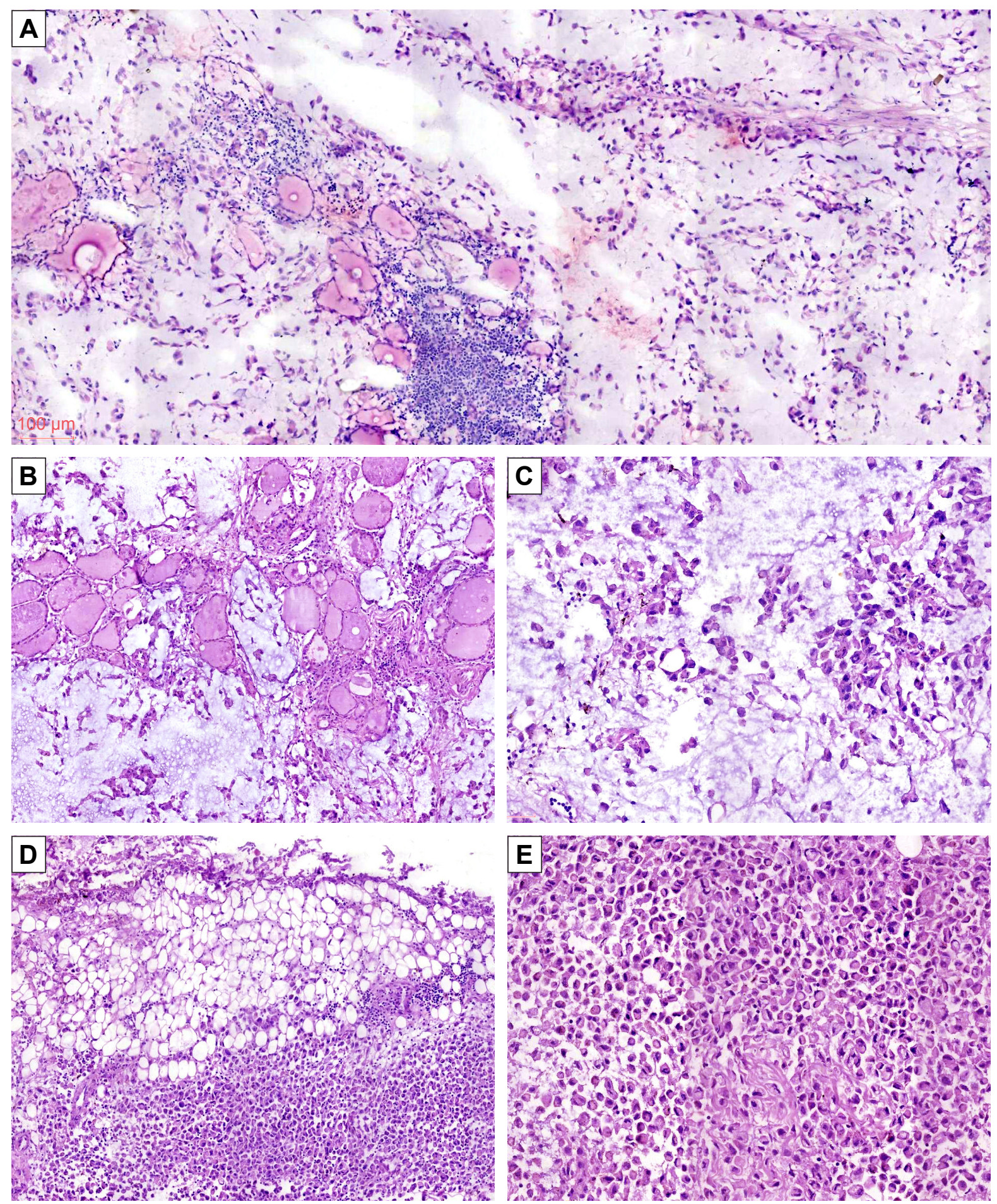

Figure 2 Histological features of the current case. (A) The tumor characterized by abundant extracellular mucus, and the tumor cells were arranged in small nests or trabeculae (frozen section, magnification $\times 100$ ). In the remnant thyroid tissues, we can observe the background of Hashimoto's thyroiditis. (B and $\mathbf{C}$ ) In most areas, the tumor cells were arranged in small nests or trabeculae, which appeared suspended in pools of abundant extracellular mucus (paraffin section, (B) magnification $\times 100$; (C) magnification $\times 200$ ). (D and $\mathbf{E}$ ) These tumor cells not only invaded into normal tissues, destructing normal thyroid structures, but also extended into extrathyroidal fat tissue. In the peripheral regions, the tumor cells aggregated and were characterized by acidic muco-substances that diffusely filled the cytoplasm and dislodged the nucleus to one pole of the cell (paraffin section, (D) magnification $\times 100$; (E) magnification $\times 200$ ).

relatively unfavorable prognosis remains to be determined in the long-term follow-up of our patient.

When we faced a primary thyroid tumor with abundant extracellular mucus, a metastasis from a mucinous carcinoma should always be the first consideration. It is hard to distinguish between them in histological images, and the mucin staining and transmission electron microscopy make no sense to distinguish between primary and secondary mucinous 


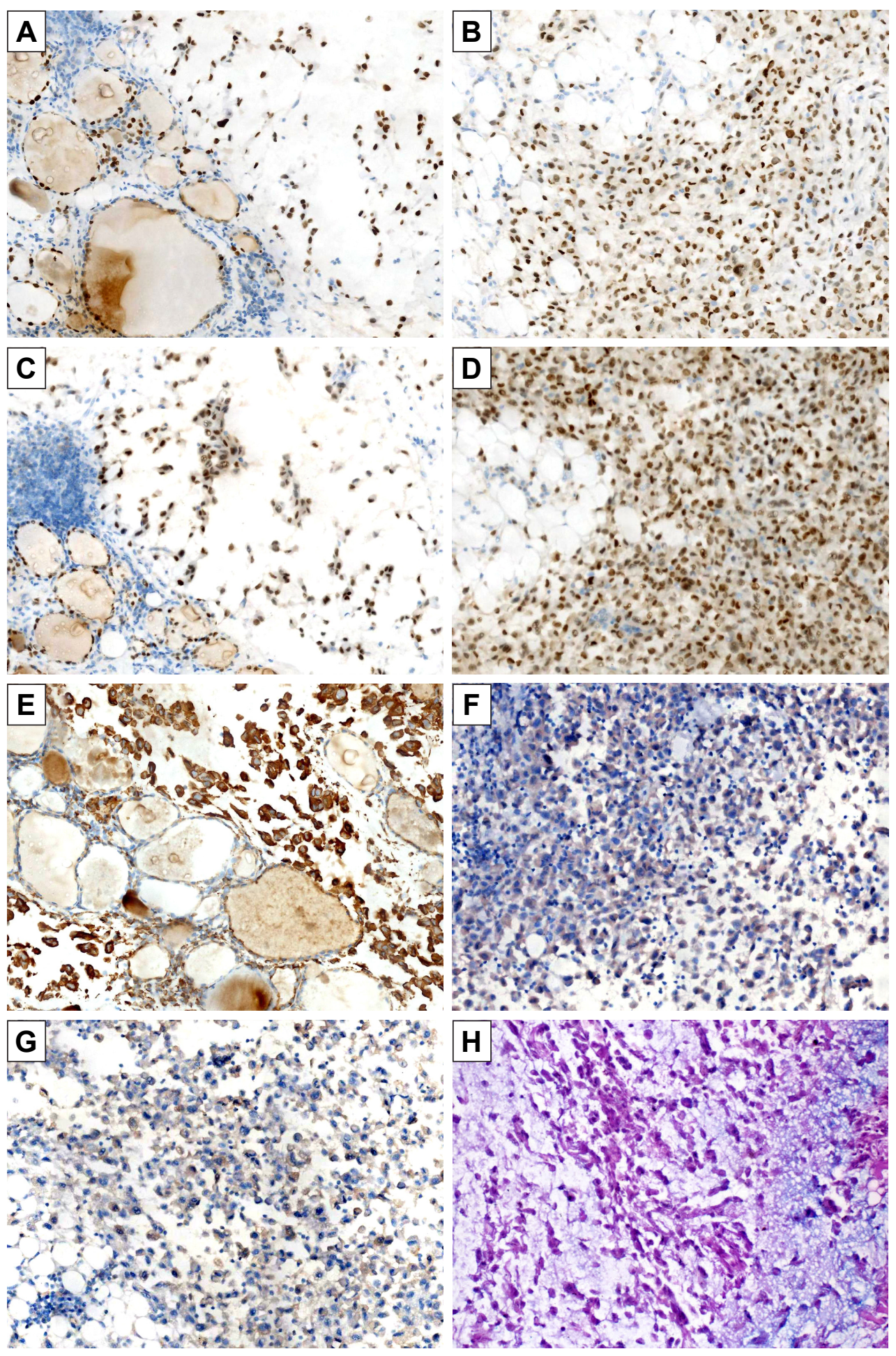

Figure 3 Immunohistochemical staining. The tumor cells were diffusely positive for TTF-I (A and B), PAX8 (C and D), and vimentin (E), but negative for CDX2, Desmin (F), and MyoDI (G). The abundant extracellular mucoid matrix was stained positively for AB-PAS (H).

Abbreviation: TTF-I, thyroid transcription factor-I.

adenocarcinoma. ${ }^{3}$ Although thyroid metastasis often come from clinically occult bronchial or renal carcinomas, the role of clinical screening in searching for a primary extrathyroidal tumor is limited. ${ }^{3}$ Using a panel of immunohistochemical makers seems the only way worth trusting to solve this thorny issue. Mucin-producing tumor cells simultaneously expressing thyroglobulin, TTF-1, or PAX8 are reliable for the diagnosis of primary mucinous carcinoma, because these signs indicate that tumor cells possess the ability to differentiate into thyroid tissue. It is still not clear about the histogenesis of primary mucinous carcinoma of thyroid gland, some scholars posed a hypothesis that these mucin-producing 
Table I Summary of clinical data of reported primary mucinous carcinoma

\begin{tabular}{|c|c|c|c|c|c|c|}
\hline Case & Authors & A/G & Tumor size $(\mathrm{cm})$ & Treatment & Metastasis & Follow-up \\
\hline 1 & $\begin{array}{l}\text { Diaz-Perez et al }{ }^{2} \\
(1976)\end{array}$ & $44 / M$ & $5 \times 4 \times 3$ (right) & $\begin{array}{l}\text { Hemithyroidectomy } \\
\text { immediately after } \\
\text { diagnosis, followed by } \\
\text { total thyroidectomy+ND }\end{array}$ & NM & 7 years, NED \\
\hline 2 & $\begin{array}{l}\text { Sobrinho-Simoes } \\
\text { et } \mathrm{a}^{3}(1986)\end{array}$ & $56 / M$ & $8 \times 6 \times 2$ (left) & Total thyroidectomy+ND & $\begin{array}{l}\mathrm{LN}+ \\
\text { Lung+ } \\
\text { Spine+ }\end{array}$ & $\begin{array}{l}\text { I year, recurrence (intestinal tract and lungs) } \\
\text { Tx: RT and } \mathrm{CH}(5 \mathrm{FU}) \\
2 \text { years, DOD }\end{array}$ \\
\hline 3 & $\begin{array}{l}\text { Cruz et al } \\
(1991)\end{array}$ & $32 / F$ & $6 \times 2.5 \times 1.5$ & Total thyroidectomy+ND & $\begin{array}{l}\mathrm{LN}+ \\
\text { Lung+ } \\
\text { Skin+ }\end{array}$ & $\begin{array}{l}2 \text { months, recurrence (thyroid gland, skin, and } \\
\text { lungs) } \\
\text { Tx: iodine therapy, RT, CH (BLM, VCR, ADM) } \\
8 \text { months, DOD }\end{array}$ \\
\hline 4 & $\begin{array}{l}\text { Kondo et al }{ }^{5} \\
(2005)\end{array}$ & $82 / F$ & $3 \times 2 \times 2$ (right) & Hemithyroidectomy+ND & $\begin{array}{l}\text { LN+ } \\
\text { Skin+ }\end{array}$ & $\begin{array}{l}2 \text { years, recurrence (LN and skin) } \\
\text { Tx: surgery and iodine therapy } \\
4 \text { years, DOD }\end{array}$ \\
\hline 5 & $\begin{array}{l}\text { D'Antonio et al } \\
(2007)\end{array}$ & $62 / F$ & NM & $\begin{array}{l}\text { Total thyroidectomy+ND } \\
\text { (incomplete resection) }\end{array}$ & $\mathrm{LN}+$ & 6 months, DOD \\
\hline 6 & $\begin{array}{l}\text { Mnif et al } \\
(20 \mid 3)\end{array}$ & $56 / M$ & $\begin{array}{l}4 \times 3 \times 2 \text { (left) } \\
3 \times 3 \times 2 \text { (right) }\end{array}$ & $\begin{array}{l}\text { Total thyroidectomy+ND } \\
\text { (incomplete resection) }\end{array}$ & $\mathrm{LN}+$ & I month, DOD \\
\hline 7 & $\begin{array}{l}\text { Matsuo et } \mathrm{al}^{7} \\
(2016)\end{array}$ & $8 \mathrm{I} / \mathrm{F}$ & NM (right) & Hemithyroidectomy & $\mathrm{LN}+$ & $\begin{array}{l}10 \text { months, recurrence }(\mathrm{LN}) \\
\text { Tx: total thyroidectomy+TSH suppression } \\
\text { therapy } \\
6 \text { years, NED }\end{array}$ \\
\hline 8 & $\begin{array}{l}\text { Bajja et al }{ }^{9} \\
(2017)\end{array}$ & $74 / M$ & $3.5 \times 2.5$ (right) & Total thyroidectomy+ND & $\begin{array}{l}\text { LN+ } \\
\text { Lung+ }\end{array}$ & 4 months, DOD \\
\hline 9 & Present case & $74 / F$ & $\begin{array}{l}5.6 \times 4 \times 2.5 \text { (right) } \\
2.2 \times 1.5 \times 0.8 \text { (left) }\end{array}$ & Total thyroidectomy+ND & $\mathrm{LN}+$ & 9 months, NED \\
\hline
\end{tabular}

Abbreviations: A/G, age (years)/gender; M, male; F, female; LN, lymph node; ND, neck dissection; NED, no evidence of disease; DOD, died of disease; $\mathrm{RT}$, radiotherapy; $\mathrm{CH}$, chemotherapy; 5FU, 5-fluorouracil; Tx, treatment; BLM, bleomycin; VCR, vincristine; ADM, adriamycin; NM, not mentioned; TSH, thyroidstimulating hormone.

cells came from thyroglossal duct remnant or ectopic salivary gland, while some people thought an ultimobranchial body remnant is more likely, specifically, via mucin-containing follicles. ${ }^{1}$ Neither hypothesis has been definitely proved and they still need to be further explored.

Once the primary tumor of the thyroid gland with the ability to produce mucin has been confirmed, a series of tumors should be included in the differential diagnosis, such as papillary carcinomas, follicular carcinomas, and medullary carcinomas. In this case, the absence of the nuclear characters of papillary carcinoma and capsule invasion or capsular vascular invasion excluded papillary carcinoma and follicular carcinoma. The tumor cells were negative for CEA and calcitonin, which, together with the normal levels of calcium, ruled out medullary carcinoma. Considering the tumor cells were diffusely positive for vimentin, mesenchymal sarcoma and anaplastic thyroid carcinoma should also be distinguished in this case. However, both mesenchymal sarcoma and anaplastic thyroid carcinoma seldom show an extracellular mucoid matrix; even if they do, the mucoid matrix only represents mucinous degeneration, but not the production by the epithelium, and common thyroid-lineage markers such as TTF-1 and thyroglobulin are usually absent in these tumors. Meanwhile the positive ratio of cells for PAX8 staining was not high. ${ }^{1}$ Therefore, mesenchymal sarcoma and anaplastic thyroid carcinoma could both be excluded.

Solid mucoepidermoid carcinoma should also be considered, as it can also produce mucin and concurrently express TTF-1 and thyroglobulin..$^{18,19}$ However, we did not find the epidermoid cell, clear cell, or intermediate cell after observing the whole sections. Therefore, we finally make a diagnosis of mucinous carcinoma instead of mucoepidermoid carcinoma.

According to the limited experience in treatment, we considered it necessary to discuss the clinical treatment and prognosis of primary mucinous carcinoma. Most of the cases indicate that primary mucinous carcinoma has a worse prognosis than common thyroid carcinoma. Of the eight patients with follow-up, six died of metastatic disease at 6 months to 4 years after diagnosis. Of the nine cases, including the current case, six underwent total thyroidectomy plus 
excision of cervical regional lymph nodes, one underwent hemithyroidectomy plus excision of cervical regional lymph nodes, and one underwent hemithyroidectomy. Although radiotherapy, chemotherapy, 5-fluorouracil treatment, and TSH suppression therapy were applied for treatment, the patient did not benefit from the treatment. Therefore, complete resection may be a suitable option for this tumor. ${ }^{7}$ In addition, some scholars pointed out that TSH suppression therapy may be a suitable option for postoperative adjuvant therapy and helpful for long-term survival. ${ }^{7}$ In general, the prognosis is not favorable, and about $50 \%$ of the patients died of the disease or experienced tumor recurrence. Complete surgical resection is a key factor which contributes to the long-term survival.

\section{Conclusion}

Here, we reported a rare case of primary mucous carcinoma of the thyroid gland with signet-ring-cell differentiation and formed diffuse infiltration among the thyroid follicles instead of "pushing" invasion. This type of signet-ring-cell with acidic muco-substance has never been reported, to our knowledge. Moreover, a panel of immunohistochemical markers were applied to confirm this cytological feature is representative for signet-ring-cell differentiation instead of rhabdoid differentiation. We reported this case to remind pathologists of this uncommon histological and cytological type of mucinous carcinoma.

\section{Acknowledgments}

We thank the patient, who requested anonymity, for agreeing to our report and for providing a detailed medical history. Informed consent was obtained from the patient for the publication of this case report and any accompanying images.

This work was supported by the National Natural Science Foundation of China (Grant No 81302312 to Yang Liu and No 81672302 to Di Zhang), Natural Science Foundation of Liaoning Province (Grant No 20170540989 to Yang Liu), The scientific research project of the Liaoning Provincial Education Department (Grant No LK201638 to Di Zhang), and Regional Science and Technology Development Foundation of Tacheng (Grant No 2017485 to Qie-Re Guli).

\section{Author contributions}

All authors contributed toward data analysis, drafting and critically revising the paper and agree to be accountable for all aspects of the work.

\section{Disclosure}

The authors report no conflicts of interest in this work.

\section{References}

1. Lloyd RV, Osamura RY, Klöppel G, Rosai J, World Health Organization, International Agency for Research on Cancer. WHO Classification of Tumours of Endocrine Organs. Lyon: IARC; 2017.

2. Diaz-Perez R, Quiroz H, Nishiyama RH. Primary mucinous adenocarcinoma of thyroid gland. Cancer. 1976;38(3):1323-1325.

3. Sobrinho-Simoes M, Stenwig AE, Nesland JM, Holm R, Johannessen JV. A mucinous carcinoma of the thyroid. Pathol Res Pract. 1986; 181(4):464-471.

4. Cruz MC, Marques LP, Sambade C, Sobrinho-Simões M. Primary mucinous carcinoma of the thyroid. Surg Pathol. 1991;4:281-289.

5. Kondo T, Kato K, Nakazawa T, Miyata K, Murata S, Katoh R. Mucinous carcinoma (poorly differentiated carcinoma with extensive extracellular mucin deposition) of the thyroid: a case report with immunohistochemical studies. Hum Pathol. 2005;36(6):698-701.

6. D'Antonio A, Addesso M, De Dominicis G, Boscaino A, Liguori G, Nappi O. Mucinous carcinoma of thyroid gland. Report of a primary and a metastatic mucinous tumour from ovarian adenocarcinoma with immunohistochemical study and review of literature. Virchows Arch. 2007;451(4):847-851

7. Matsuo M, Tuneyoshi M, Mine M. Primary mucinous carcinoma with rhabdoid cells of the thyroid gland: a case report. Diagn Pathol. 2016;11(1):48

8. Mnif H, Chakroun A, Charfi S, Ellouze S, Ghorbel M, SallemiBoudawara T. Primary mucinous carcinoma of the thyroid gland: case report with review of the literature. Pathologica. 2013;105(4): $128-131$

9. Bajja MY, Benassila FZ, Abada RL, Mahtar M, Chadli A. Mucinous carcinoma of the thyroid: A case report and review of the literature. Ann Endocrinol (Paris). 2017;78(1):70-73.

10. Squillaci S, Pitino A, Spairani C, Ferrari M, Carlon E, Cosimi MF. Mucinous variant of follicular carcinoma of the thyroid gland: case report and review of the literature. Int J Surg Pathol. 2016;24(2):170-176.

11. Bosman FT, World Health Organization, International Agency for Research on Cancer. WHO Classification of Tumours of the Digestive System. 4th ed. Lyon: IARC Press; 2010.

12. Lakhani SR, Ellis IO, Schnitt SJ, et al. WHO Classification of Tumours of the Breast. 4th ed. Lyon: IARC; 2012.

13. Kurman RJ, Carcangiu ML, Herrington CS, Young RH, World Health Organization, International Agency for Research on Cancer. WHO Classification of Tumours of Female Reproductive Organs. Lyon: IARC; 2014

14. Agarwal S, Sharma MC, Aron M, Sarkar C, Agarwal N, Chumber S. Poorly differentiated thyroid carcinoma with rhabdoid phenotype: a diagnostic dilemma - report of a rare case. Endocr Pathol. 2006;17(4):399-405.

15. Alsop JE, Yerbury PJ, O’Donnell PJ, Heyderman E. Signet-ring cell microfollicular adenoma arising in a nodular ectopic thyroid. A case report. J Oral Pathol. 1986;15(10):518-519.

16. Schroder S, Bocker W. Signet-ring-cell thyroid tumors. Follicle cell tumors with arrest of folliculogenesis. Am J Surg Pathol. 1985;9(9): 619-629.

17. Farhat NA, Onenerk AM, Krane JF, Dias-Santagata D, Sadow PM, Faquin WC. Primary benign and malignant thyroid neoplasms with signet ring cells: cytologic, histologic, and molecular features. Am J Clin Pathol. 2017;148(3):251-258.

18. Larson RS, Wick MR. Primary mucoepidermoid carcinoma of the thyroid: diagnosis by fine-needle aspiration biopsy. Diagn Cytopathol. 1993;9(4):438-443.

19. Minagawa A, Iitaka M, Suzuki M, et al. A case of primary mucoepidermoid carcinoma of the thyroid: molecular evidence of its origin. Clin Endocrinol (Oxf). 2002;57(4):551-556. 


\section{Publish your work in this journal}

OncoTargets and Therapy is an international, peer-reviewed, open access journal focusing on the pathological basis of all cancers, potential targets for therapy and treatment protocols employed to improve the management of cancer patients. The journal also focuses on the impact of management programs and new therapeutic agents and protocols on

patient perspectives such as quality of life, adherence and satisfaction. The manuscript management system is completely online and includes a very quick and fair peer-review system, which is all easy to use. Visit http://www.dovepress.com/testimonials.php to read real quotes from published authors.

Submit your manuscript here: http://www.dovepress.com/oncotargets-and-therapy-journal 